\title{
Pemanfaatan Astrolabe dalam Perhitungan Waktu Shalat di SMA Sains dan Tahfidz Al-Ammar Tanjung Morawa
}

\author{
Hasrian Rudi Setiawan ${ }^{1 *}$, Arwin Juli Rakhmadi ${ }^{1}$, Muhammad Hidayat ${ }^{1}$, Hariyadi Putraga ${ }^{1}$ \\ ${ }^{1}$ Universitas Muhammadiyah Sumatera Utara, Jl. Kapten Muchtar Basri No.3, Glugur Darat II, Kec. Medan Tim., Kota
}

Medan, Sumatera Utara 20238

*Email koresponden: hasrianrudisetiawan@gmail.com

\section{ARTICLE INFO}

Article history

Received: 27 Jul 2021

Accepted: 21 Nov 2021

Published: 31 Des 2021

\section{Kata kunci:}

Astrolabe;

Astronomi;

Waktu sholat;

\section{Keywords:}

Astrolabe;

Astronomy;

Prayer times;

\begin{abstract}
A B S T R A K
Background: Perhitungan waktu shalat didasai atau ditentukan berdasarkan posisi Matahari ataupun data Matahari, baik pada saat yang bersangkutan (jam, hari, bulan dan tahun) maupun data rata-rata. Ketepatan penentuan waktu shalat, disampng tergantung pada sistem atau rumus-rumus juga tergantung pada ketepatan pengamblan data, seperti data Matahari maupun data lain yang dibutuhkan dalam perhitungan. Astrolabe merupakan salah satu instrumen astronomi yang dapat digunakan dalam pengambilan data Matahari maupun penentuan waktu shalat Metode: Ada tiga tahap metode pelaksanaan yang telah dirancang dalam pengabdan kali ini yaitu tahap persiapan, tahap pelaksanaan dan tahap evaluasi program. Hasil: Berdasarkan hasil pengabdian di SMA Sains dan Tahfidz Al-Ammar didapatkan bahwa peserta didik memahami akan pentnngnya instrumen Astrolabe dan dapat menggunakan alat Astrolabe khususnya dalam perhtungan waktu shalat. Kesimpulan: Peserta didik terdorong untuk meningkatkan pemahaman maupun penggunaan Astrolabe pada materi-materi yang lain sehingga dapat bermanfaat bagi kehidupan, agama, bangsa dan negara.
\end{abstract}

\section{A B S T R A C T}

Background: The prayer time is based on the position of the Sun or the Sun data, both at the time in question (hours, days, months and years) and average data. The accuracy of the timing of prayer, which depends on the system or formulas also depends on the accuracy of the data, such as solar data and other data needed in the calculation. Astrolabes are one of the astronomical instruments that can be used in the taking of solar data and the determination of prayer times. Method: There are three stages of implementation methods that have been designed in the preparation stage, the implementation stage and the evaluation stage of the program. Results: Based on the results of devotion at Science High School and Tahfidz Al-Ammar obtained that learners understand the attachment of Astrolabe instruments and can use Astrolabe tools, especially in prayer time. Conclusion: Learners are encouraged to increase the understanding and use of Astrolabe in other materials so that it can benefit the life, religion, nation and state.

( 2021 by authors. Lsens Jurnal Solma, UHAMKA, Jakarta. Artkel n bersfat open access yang ddstrbuskan d bawah syarat dan ketentuan Creatve Commons Attrbuton (CC-BY) Icense.

\section{PENDAHULUAN}

Tujuan pendidikan Nasional, secara umum sebagaimana diamanahkan undangundang, adalah mengembangkan potensi peserta didik agar menjadi manusia yang beriman dan bertakwa kepada Tuhan Yang Maha Esa, berakhlak mulia 
berilmu, cakap, kreatif, mandiri dan menjadi warga negara yang berdemokrasi serta bertanggung jawab (Undang-Undang No 20 Tahun 2003 Tentang Sistem Pendidikan Nasional Bab II Pasal 3, 2003). Dari rumusan tersebut, dapat dipahami bahwa pendidikan bukan terbatas hanya perihal transfer ilmu, melainkan juga jiwa dan kepribadian. Hal yang sama juga dikemukakan Nasr (1994), yang menyatakan tujuan pendidikan bukan hanya untuk melatih pikiran, melainkan juga untuk melatih keseluruhan potensi sebagai manusia. Itu sebabnya, pendidikan tidak hanya berimplikasi pada pengajaran ataupun transmisi ilmu (ta'lim) tetapi juga melatih keseluruhan pribadi pelajar (tarbiyah) (ButarButar, 2016). Guru, dalam hal itu, bukan sebatas pengajar (mu'alim) yang mentransfer ilmu, melainkan juga pendidik (murabbi), yang melatih jiwa dan kepribadian (Qulub, 2017).

Terkait tujuan pendidikan, menurut Al-Attas (1999) menggariskan secara sederhana; meskipun harus dipahami secara mendalam, yaitu upaya melahirkan manusia yang baik, bukan semata masyarakat yang baik. Hal itu karena masyarakat terdiri dari individu, sehingga melahirkan seorang yang baik akan melahirkan masyarakat yang baik, tetapi tidak sebaiknya. Ia menyatakan bahwa pendidikan sejatinya adalah pembuat struktur masyarakat yang ideal. Sejalan dengan uraian diatas saat SMA Sains Plus dan Tahfidz Qur'an Al-Ammar menerapkan Pendidikan yang berbasis Islamisasi pengetahuan sehingga diharapkan peserta didik dapat mengintegrasikan dan mengislamisasi ilmu pengetahuan agar ilmu pengetahuan Islam dapat kembali seperti di abad pertengahan.

Terkait itu, secara praktis Hafidhuddin menjelaskan dimensi-dimensinya. Terkhusus lingkup sains Islam, ada tiga aktivitas yaitu Pertama, pendalaman terhadap teori-teori sains sebagai wujud sikap kritis ilmuwan muslim. Kedua, mewarnai bahasan sains dengan aspek-aspek metafisika yang selaras dengan nilai-nilai Islam. Ketiga, mengarahkan aplikasi sains kedalam teknologi yang menjamin keberlangsungan penghargaan terhadap nilai-nilai kemanusiaan (Handrianto, 2019). Dalam proses belajar mengajar, untuk mencapai tujuan pembelajaran media memegang peranan penting didalamnya. Hal ini dikarenakan di dalam belajar tidak semuanya menyangkut hal-hal yang konkrit dalam konsep maupun faktanya. Bahkan dalam realitasnya, belajar seringkali bersentuhan dengan hal-hal yang bersifat kompleks maya dan berada dibalik realitas (Slameto, 2010).

Dalam proses pembelajaran, media tidak sekedar menjadi alat bantu dalam pembelajaran, melainkan juga merupakan sumber belajar (Suryani et al., 2018). Beberapa fungsi penggunaan media dalam pembelajaran yang didasarkan dari segi penggunaannya antara lain membantu untuk mempercepat pemahaman dalam proses pembelajaran (Miftah, 2013), memperjelas penyajian pesan pesan agar tidak bersifat verbalistis, mengatasi keterbatasan ruang, pembelajaran lebih komunikatif dan produktif, waktu pembelajaran bisa dikondisikan, menghilangkan kebosanan siswa dalam mempelajarai sesuatu (Setiawan, 2020).

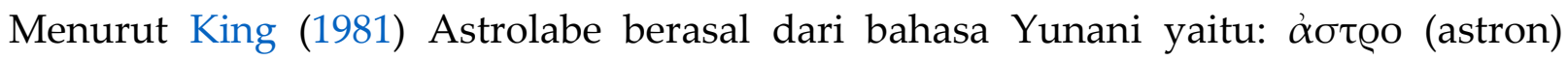
artinya bintang, dan גáßos (labos) artinya mengambil. Kedua kata ini bergabung membentuk astrolabos, yang artinya menempatkan bintang. Astrolabe adalah instrumen astronomi klasik, deskripsi dua dimensi dari bola langit (Angelo, 2006). Pada zaman dahulu, astronom menggunakan alat ini untuk menghitung posisi benda langit, 
menghitung panjang hari, panjang satu tahun, menghitung jarak sudut antara dua benda langit, mencari arah mata angin yang sebenarnya, menghitung ketinggian dan azimuth bintang-bintang di langit. Astrolabe menggabungkan dua sistem koordinat dengan sempurna, yaitu system koordinat horizon dan system koordinat ekuator.

Banyak sejarawan mengatakan bahwa konsep "astrolabe" pertama kali diajukan antara 300 dan 200 SM (Zaimeche, 2002). Sedangkan ilmuwan Muslim pertama yang menciptakan Astrolabe adalah Abu Ishaq Muhammad bin Ibrahim al-Fazari, ahli astronomi dari pemerintahan Khalifah Abu Jafar Al-Manshur Dinasti Abassiah. Seiring laju perkembangan ilmu pengetahuan, astrolabe menjadi instrument astronomi penting, bahkan semakin menemukan arti pentingnya karena kedudukan dan fungsinya yang signifikan dalam kehidupan. Alat ini terdiri dari banyak komponen yaitu mater, plates, rete, rule, alidade, throne, limb, pin, dan horse (Mitchell, 2011).
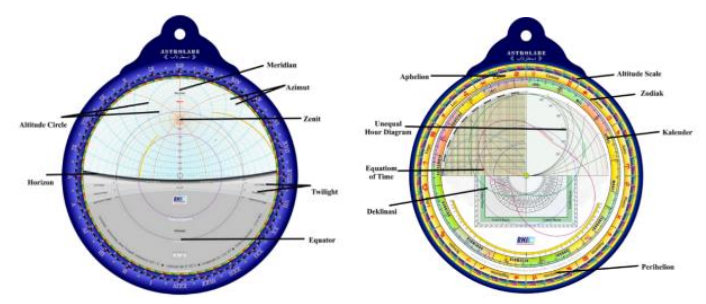

Gambar 1. Astrolabe RHI

Adapun Astrolabe yang digunakan dalam program ini adalah Astrolabe RHI. Astrolabe RHI termasuk astrolabe modern karena bahan dan teknik pembuatannya lebih modern seperti menggunakan bahan akrilik dan dalam pembuatannya menggunakan desain komputer serta teknik laser printing dan laser cutting sehingga alat ini memiliki akurasi yang cukup bagus (Rohmah, 2017) dan materi yang dijelaskan yaitu materi tentang waktu shalat. Shalat adalah ibadah yang tidak bisa ditinggalkan (Hambali, 2011), waktu shalat telah ditentukan dalam sumber-sumber Syariah, al-Quran dan sunnah Nabi saw (Majelis Tarjih dan Tajdid Pimpinan Pusat Muhammadiyah, 2009)

\section{MASALAH}

Berdasarkan hasil wawancara penulis dengan kepala SMA Sains Plus dan Tahfidz Qur'an AlAmmar Ibu Fauziah dan ketua Lembaga Sains SMA Sains Plus dan Tahfidz Qur'an Al-Ammar yaitu Bapak Heru, saat ini pemanfaatan dan penggunaan media dalam pembelajaran Ilmu Falak masih belum terlalu optimal baik dari kemampuan dan pengetahuan guru maupun sarana media tersebut, di SMA Sains Plus dan Tahfidz Qur'an Al-Ammar terdapat beberapa instrument Falak seperti teleskop, Astrolabe, Rubu Al-Mujayyab. Namun jika ingin siswa dapat lebih memahami hingga praktek penggunaan maka diperlukan tambahan dari alat-alat tersebut yang bisa dibuat sendiri (handmade). Adapun alat yang akan di kembangkan yaitu alat Astrolabe.

Selama ini Astrolabe hampir tidak pernah diajarkan penggunaannya pada mata pelajaran Ilmu Falak baik tingkat sekolah menengah atas maupun tingkat perguruan tinggi di Indonesia sama halnya di SMA Sains Plus dan Tahfidz Qur'an Al-Ammar. Astrolabe lebih sering diperkenalkan dalam hal sejarah dan teori, padahal fungsi dan kegunaanya sangat banyak seperti menentukan waktu shalat, arah kiblat, gerhana, posisi bintang dan lainnya.

Dari uraian diatas menunjukkan pemanfaatan, penggunaan dan pembuatan Astrolabe belum pernah disampaikan di SMA Sains Plus dan Tahfidz Qur'an Al-Ammar khususnya pada mata pelajaran Ilmu Falak. Oleh karena itu peneliti tertarik untuk melakukan program kemitraan masyarakat di SMA Sains Plus dan Tahfidz Qur'an Al-Ammar. 


\section{METODE PELAKSANAAN}

Ada tiga tahap metode pelaksanaan yang telah dirancang yaitu pertama, tahap persiapan dimana tim pengusul program PKM mengadakan survey lapangan untuk melihat permasalahan yang terjadi di lapangan. Kemudian tim langsung berkoordinasi dengan pihak sekolah dan pihak pengurus SMA Sains Plus dan Tahfidz Qur'an AlAmmar Dilanjutkan dengan pengurusan surat mitra, mengundang anggota MGMP dan penyiapan bahan dan perlengkapan yang dibutuhkan pada saat pengembangan program dilaksanakan.

Tabel 1. Tahapan, Waktu dan Outcome dar pelaksanaan kegatan

\begin{tabular}{|c|c|c|}
\hline Tahap & Waktu & Outcome \\
\hline Persiapan & 27 Mei 2021 & $\begin{array}{l}\text { 1. Mempersiapkan nstrument atau media } \\
\text { 2. Melakukan kajian Pustaka } \\
\text { 3. Memilih metode } \\
\text { 4. Mempersiapkan buku panduan }\end{array}$ \\
\hline Pelaksanaan & 5 Juni 2021 & $\begin{array}{l}\text { 1. Pembuatan Prototype Astrolabe } \\
\text { 2. Pembukaan dan Pengenalan } \\
\text { 3. Presentasi dan Tanya Jawab } \\
\text { 4. Praktik Langsung }\end{array}$ \\
\hline
\end{tabular}

Tahap kedua yaitu tahap pelaksanaan. Di dalam tahap ini kegiatan yang dilakukan adalah mempersiapkan prototype instrument Astrolabe, melakukan seminar tentang pentingnya Pemanfaatan Instrumen Astrolabe Pada Mata Pelajaran Ilmu Falak di SMA Sains Plus dan Tahfidz Qur'an Al-Ammar Tanjung Morawa, melakukan penyuluhan tentang Penggunaan Astrolabe pada Materi Waktu Shalat, melakukan work shop pembuatan media pembelajaran sederhana guru mampu membantu siswa belajar di rumah dalam menunjang pendidikan siswa, peserta akan mempraktekan sendiri penggunaan Instrumen Astrolabe, memberikan penyuluhan dan tes tentang keberhasilan Pemanfaatan Instrumen Astrolabe Pada Mata Pelajaran Ilmu Falak di SMA Sains Plus dan Tahfidz Qur'an Al-Ammar Tanjung Morawa. Selanjutnya akan dilaksanakan monitoring, hal ini untuk mengetahui apakah guru-guru mengaplikasikan Instrumen Astrolabe di sekolah. Tahap ketiga yaitu tahap evaluasi program untuk mengetahui tentang sejauh mana keberhasilan yang dapat dicapai dari program ini dan melakukan perbaikanperbaikan pada proses yang dirasa kurang optimal.

\section{HASIL DAN PEMBAHASAN}

Hasil yang dicapai dari Pemanfaatan Instrumen Astrolebe Pada Mata Pelajaran Ilmu Falak di SMA Sains dan Tahfidz Qur'an Al-Ammar Tanjung Morawa sebagai berikut:

\section{Survey Awal}

Kegiatan ini terdiri dari dua kali pertemuan, yaitu: Pertama, mengunjungi kepala sekolah SMA Sains dan Tahfidz Qur'an Al-Ammar Tanjung Morawa. Pertemuan tersebut dilaksanakan pada tanggal 09 Februari 2021 Pada pertemuan ini membahas masalah teknis pelaksanaan di lokasi kegiatan program kemitraan masyarakat yang telah ditentukan diawal, seperti jumlah peserta dari SMA Sains dan Tahfidz Qur'an Al-Ammar Tanjung Morawa, menentukan waktu 
pelaksanaan program kemitraan masyarakat dan kemudian menentukan materi yang akan disampaikan terkait pembuatan media pembelajaran. Hal ini tentunya sangat penting untuk mempersiapkan dan mempelajari materi yang terkait dengan Instrumen Astrolabe.

Kedua, Mengadakan pertemuan dengan ketua lembaga sains SMA Sains dan Tahfidz Qur'an Al-Ammar Tanjung Morawa. Pertemuan ini dilaksanakan pada tanggal 19 Februari 2021 Dalam pertemuan ini panitia PKM membicarakan hal teknis terkait program yang akan dilaksanakan, seperti pengaturan ruangan yang akan digunakan, masalah administrasi dan lain sebagainya. Dan pada pertemuan ini panitia PKM juga memberikan informasi kepada Kepala sekolah SMA Sains dan Tahfidz Qur'an Al-Ammar Tanjung Morawa terkait waktu pelaksanaan program kemitraan masyarakat tersebut dan jumlah peserta dari setiap masing-masing utusan yang telah ditentukan oleh panitia PKM

\section{Persiapan Pelaksanaan Program Kemitraan Masyarakat}

Setelah panitia PKM mendapat saran, masukan dan persetujuan dari Kepala sekolah SMA Sains dan Tahfidz Qur'an Al-Ammar Tanjung Morawa. Mata pada tahap berikutnya panitia PKM melakukan persiapan teknis maupun non teknis terkait kegiatan program kemitraan masyarakat yang akan dilakukan. Adapun persiapan yang dilakukan sebelum pelaksanaan kegiatan program kemitraan masyarakat adalah: Pertama, Mempersiapkan instrument atau media yang akan disampaikan dalam kegitan pengabdian masyarakat tersebut. Kedua, Melakukan studi pustaka mengenai materi yang sesuai untuk di berikan pelatihan kepada peserta didik. Ketiga, Memilih metode serta strategi yang tepat untuk menyampaikan materi pelatihan pembuatan media pembelajaran tersebut. Keempat. Mempersiapkan buku panduan atau buku ajar mengenai pemanfaatan media pembelajaran tersebut.

\section{Pelaksanaan Program Kemitraan Masyarakat}

Pelaksanaan kegiatan program kemitraan masyarakat yang dilaksanakan di Jl.Limau Manis, Medan Senembah, Tanjung Morawa. Kegiatan ini berlangsung pada Sabtu 05 Mei 2021. Pertama, Sesi Pembuatan Prototype Astrolabe. Pembuatan prototype Astrolabe menggunakan bahan dari kertas dan juga cutting stiker dengan ukuran yang lebih kecil dari aslinya. Adapun prototype Astrolabe ini nantinya diberikan kepada peserta didik sehingga para peserta didik dapat menggunakannya secara langsung. Berikut ini merupakan proses pembuatan prototype Astrolabe:

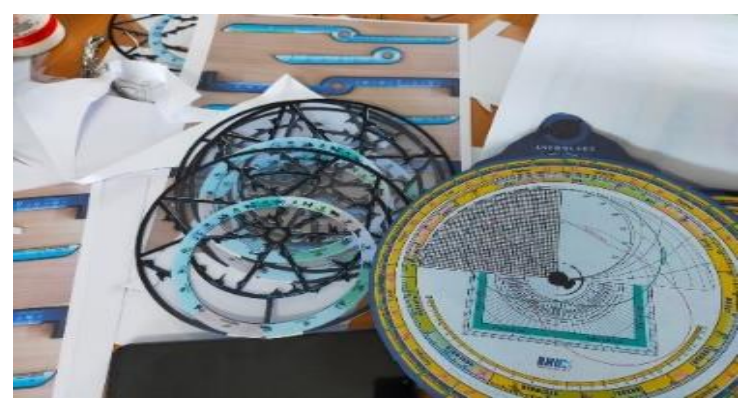

Gambar 2. Proses pembuatan prototype Astrolabe

Kedua, Sesi Pembukaan dan Pengenalan. Dalam kegiatan ini di buka oleh Pak Heru Mataviani yang merupakan ketua Lembaga sains SMA Sains Plus dan Tahfidz Qur'an Al-Ammar Tanjung Morawa dalam kata sambutannya mengatakan bahwa "pembelajaran tentang astrolabe ini sangat penting bahkan wajib dipelajari oleh anak-anak sekalian karena penggunaan astrolabe telah berkembang sejak peradaban Islam (Abad Pertengahan) yang penggunaannya meluas pada kepentingan dan kegunaan yang berhubungan dengan ibadah seperti penentuan waktu shalat, arah kiblat dll". Terlebih SMA Sains Plus dan Tahfidz Qur'an Al-Ammar Tanjung Morawa 
mengajarkan Ilmu Falak yang termuat dalam kurikulum sehingga PKM yang dilaksanakan pada kesempatan ini sangat sesuai dan membantu para siswa memahami Ilmu Falak lebih dalam melalui penggunaan instrument astronominya.

Kemudian, sesi pengenalan dalam kegiatan ini disampaikan oleh panitia PKM, yaitu: Hasrian Rudi Setiawan. Pada sesi ini di perkenalkan tentang tujuan kegiatan yang akan dilakukan dari awal sampai akhir, seperti tahapan-tahapan kegiatan pemanfaatan media pembelajaran Astrolabe, dan manfaat yang diperoleh ketika menggunakan media Astrolabe.

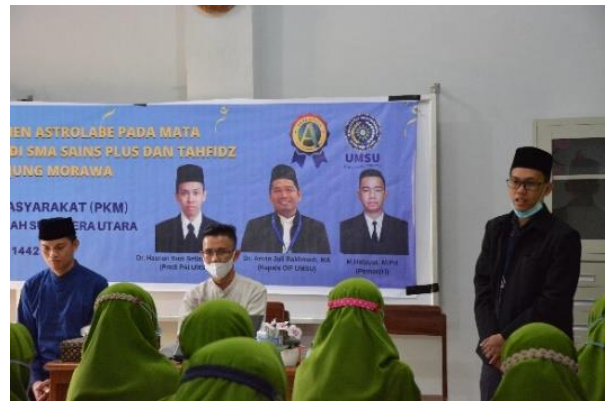

Gambar 3. Pengenalan kegiatan PKM

Ketiga, Sesi Presentasi dan Tanya Jawab. Pada tahap ini peserta pelatihan akan mendengarkan bagaimana pemanfaatan instrumen Astrolabe pada mata pelajaran Ilmu Falak. Materi. Materi tersebut disampaikan secara teori oleh Anggota Tim PKM. Penjelasan ini diawali dari sejarah Instrumen Astrolabe hingga langkah-langkah penggunaannya, Adapun pada PKM kali ini lebih fokus pada kajian menghitung waktu shalat menggunakan Astrolabe. Kemudian setelah dijelaskan secara teori bagaimana pemanfaatan instrumen Astrolabe pada mata pelajaran Ilmu Falak, maka peserta diarahkan untuk melakukan tanya jawab terkait dengan materi yang belum dipahami mengenai pemanfaatan instrumen Astrolabe pada mata pelajaran Ilmu Falak. Sangat terlihat jelas antusias peserta pelatihan, yang ditandai dengan mereka sangat bersemangat dalam bertanya mengenai penggunaan instrumen Astrolabe pada mata pelajaran Ilmu Falak tersebut.

Penjelasan instrumen Astrolabe dilaksanakan pada Sabtu 05 Mei 2021 di SMA Sains Plus dan Tahfidz Qur'an Al-Ammar Tanjung Morawa dengan mengangkat judul yaitu Pemanfaatan Instrumen Astrolabe Pada Mata Pelajaran Ilmu Falak dengan tetap memenuhi protokol Kesehatan, dalam pelaksanaanya siswa/i diberikan penjelasan terkait, sejarang fungsi dan kegunaan Astrolabe.

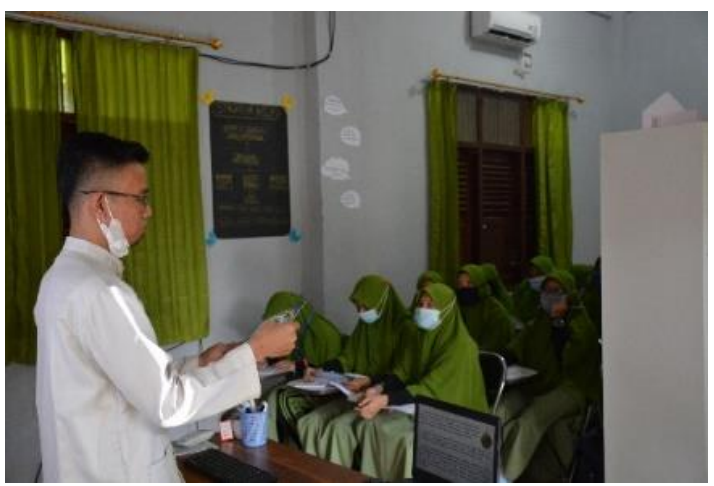

Gambar 4. Penjelasan instrumen Astrolabe

Keempat, Sesi Praktek Langsung penggunaan media instrumen Astrolabe pada mata pelajaran Ilmu Falak. Setelah materi disampaikan oleh Narasumber, terkait sejarah, manfaat dan baian-bagian dari Astrolabe, maka tahap selanjutnya adalah tahap mempraktekkan penggunaan instrumen Astrolabe pada mata pelajaran Ilmu Falak. Materi ini disampaikan oleh Hasrian Rudi Setiawan, M.Pd.I, dibantu oleh Arwin Juli Rakhmadi, MA dan Anggota Tim PKM. Pada tahap ini 
para peserta dibimbing untuk menggunakan terkait instrumen Astrolabe pada mata pelajaran Ilmu Falak tahap demi tahap mulai dari mengetahui bagian-bagian Astrolabe, mencari nilai deklinasi, equation menggunakan Astrolabe hingga menghitung waktu sholat. Terlihat peserta sangat antusias mempelajari dan menyampaikan bahwa PKM ini sangat bermanfaat dan memberikan informasi baru yang tidak kami ketahui sebelumnya. Pembelajaran Ilmu Falak menggunakan instrument Astrolabe ini ternyata sangat menarik karena berhubungan langsung pada aplikasi kehidupan sehari-hari, siswa selama ini banyak yang bertanya terkait instrumeninstrumen klasik, diharapkan dengan pemanfaatan instrumen Astrolabe pada pembelajaran Ilmu Falak disekolah dapat meningkatkan minat untuk memperdalam Astronomi maupun Ilmu Falak.

Para peserta didik diberikan prototype Astrolabe dan bersama-sama menggunakannya dengan dipandu oleh narasumber, Adapun fokus kajian pada kegiatan ini yaitu penggunaan astrolabe dalam menghitung waktu shalat. Terlihat para peserta didik sangat antusias mempelajari dan menggunakan Astrolabe sehingga alat ini dapat digunakan sebagai pembelajaran kedepannya.

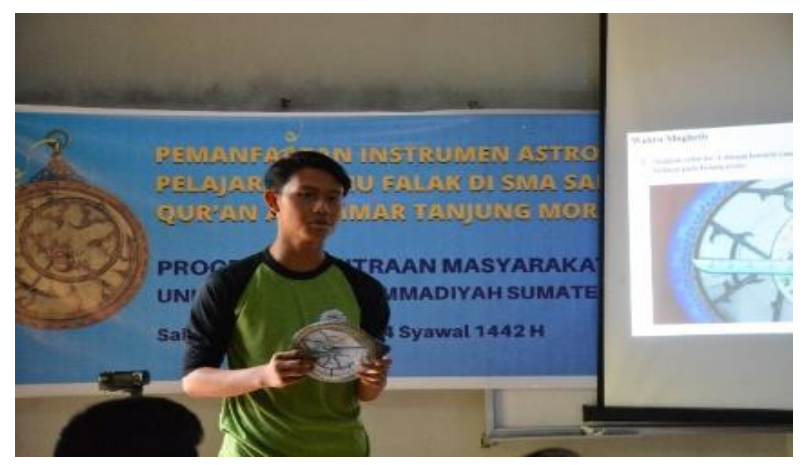

Gambar 5. Peserta didik menggunakan Astrolabe

Setelah dilakukan praktek penggunaan dan pemanfaatan instrumen Astrolabe pada mata pelajaran Ilmu Falak dan para peserta memahami pemanfaatan instrumen Astrolabe pada mata pelajaran Ilmu Falak, maka panitia PKM dan Narasumber melakukan evaluasi terhadap keberhasilan dalam kegiatan pelatihan yang telah dilakukan. Dari hasil evaluasi yang dilakukan maka terlihat hasil yang sangat memuaskan dari kegiatan pelatihan yang diselenggarakan tersebut. Secara umum setelah dilakukan pelatihan pemanfaatan instrumen Astrolabe pada mata pelajaran Ilmu Falak, maka para peserta pelatihan dapat menggunakan instrumen Astrolabe pada mata pelajaran Ilmu Falak.

Kemudian setelah dilakukan evaluasi dan telah diketahui hasil dari kegiatan pemanfaatan instrumen Astrolabe pada mata pelajaran Ilmu Falak yaitu dari soal tes yang diberikan maka kegiatan ini diakhiri dengan acara poto bersama.

\section{KESIMPULAN}

Astrolabe merupakan alat yang jarang diketahui dan memilki banyak fungsi dalam kehidupan maupun ibadah umat Islam, sehingga pembelajaran terkait instrument astronomi khususnya Astrolabe harus terus dikembangkan. Berdasarkan hasil pengabdian di SMA Sains \& Tahfidz Al-Ammar maka dapat disimpulkan bahwa peserta didik memahami akan pentingnya instrument Astrolabe dan dapat menggunakan alat Astrolabe khususnya dalam perhitungan waktu shalat, selain itu para peserta didik juga terdorong untuk meningkatkan pemahaman maupun penggunaan Astrolabe pada materi-materi yang lain sehingga dapat bermanfaat bagi kehidupan, agama, bangsa dan negara. 


\section{UCAPAN TERMA KASIH}

Ucapan terma kash terutama dtujukan kepada pember dana kegatan atau donatur. Ucapan terma kash dapat juga dsampakan kepada phak-phak yang membantu pelaksanaan kegatan.

\section{DAFTAR PUSTAKA}

Al-Attas, S. M. N. (1999). The Concept of Education. ISTAC.

Angelo, J. A. (2006). Encyclopedia of Space and Astronomy. Fact On File Inc.

Butar-Butar, A. R. (2016). Khazanah Astronomi Islam. UM Purwokerto Press.

Hambali, S. (2011). Ilmu Falak 1. Program Pascasarjana IAIN Walisongo Semarang.

Handrianto, B. (2019). Islamisasi Sains: Sebuah Upaya Mengislamkan Sains Barat Modern. INSISTS.

Undang-Undang No 20 Tahun 2003 Tentang Sistem Pendidikan Nasional Bab II Pasal 3, (2003).

King., D. A. (1981). The Origin of the Astrolabe According to the Medieval Islamic Sources. Journal for the History Arabics Science, 5(43).

Majelis Tarjih dan Tajdid Pimpinan Pusat Muhammadiyah, M. T. dan T. P. P. M. (2009). Pedoman Hisab Muhammadiyah. MTT PP Muhammadiyah.

Miftah, M. (2013). Fungsi dan Peran Media Pembelajaran Sebagai Upaya Peningkatan Kemampuan Belajar Siswa. Jurnal Kwangsan, 1(2), 95. https://doi.org/10.31800/jurnalkwangsan.v1i2.7

Mitchell, M. T. J. (2011). The Astrolabe in Theory and Practice. Creative Commons Attribution.

Nasr, S. H. (1994). Traditional Islam in the Modern Word. Colombia University Press.

Qulub, S. T. (2017). Ilmu Falak. Rajawali Press.

Rohmah, N. (2017). Astrolabe RHI Dalam Menentukan Panjang Bayangan Awal Waktu Zuhur dan Asar. UIN Walisongo Semarang.

Setiawan, H. R. (2020). Pemanfaatan Media Rubu' Al - Mujayyab Pada Pembelajaran Matematika Di Sekolah. Idrak: Journal of Islamic Education., 2(2), 223-238.

Slameto, S. (2010). Belajar dan Faktor-Faktor yang mempengaruhinya. Rineka Cipta.

Suryani, N., Setiawan, A., \& Aditin Putria. (2018). Media Pembelajaran Inovatif dan Pengembangannya (Pipih Latifah (ed.)). PT. Remaja Rosdakarya.

Zaimeche, S. (2002). Muslim Contribution to Astronomy. Jurnal Manchester: FSTC Limited, 6. 